\title{
Low dielectric loss in nano-Li-ferrite spinels prepared by sol-gel auto-combustion technique
}

\author{
MAMATA MAISNAM ${ }^{1, *}$, NANDEIBAM NILIMA ${ }^{2}$, MAISNAM VICTORY ${ }^{2}$ and \\ SUMITRA PHANJOUBAM ${ }^{2}$ \\ ${ }^{1}$ Department of Basic Sciences and Humanities, National Institute of Technology Manipur, Langol 795 004, India \\ ${ }^{2}$ Department of Physics, Manipur University, Canchipur 795 003, India
}

MS received 8 February 2015; accepted 27 August 2015

\begin{abstract}
Pure and doped nano-Li-ferrite spinels were prepared by the sol-gel auto-combustion technique. The prepared ferrites were pelleted and heat treated at different temperatures. Structural characterization was carried out on the as-prepared samples and also on the heat-treated samples using X-ray diffraction (XRD). The studies confirmed the formation of single phase with spinel structures in all the samples. The crystallite size of the samples evaluated from XRD data was found to be 17-24 $\mathrm{nm}$. Scanning electron microscopic photomicrographs revealed the microstructures and the grain size of these nanoferrites. The room-temperature dielectric constant and dielectric loss tangent, $\tan \delta$ were measured as a function of frequency in the range $100 \mathrm{~Hz}-1 \mathrm{MHz}$. These nanoferrites showed the normal dielectric dispersion behaviour. The observed dielectric constant and dielectric loss tangent were found to be much lower than those measured on substituted Li-ferrites prepared by the conventional ceramic method. The results obtained were discussed in the paper.
\end{abstract}

Keywords. Nano-Li-ferrites; sol-gel technique; X-ray diffraction; dielectric constant; $\tan \delta$.

\section{Introduction}

Spinel structured Li-ferrites are good dielectrics and they possess inherent properties like high Curie temperature, excellent square loop properties, high saturation magnetization, and low dielectric and magnetic losses. For this they have been thoroughly investigated over the decades for applications in memory core devices and high-frequency microwave devices [1,2]. Ferrites prepared by the conventional ceramic method lack good performance quality owing to certain inherent disadvantages of this method. The method is very cumbersome and time consuming. Prolong grinding and milling operations involved in the process often lead to loss of some constituent materials and also impurity pick-ups. The refractory nature of the starting materials for preparation of Liferrites by the conventional ceramic technique requires high temperature to sinter to the desired [3-6]. Such high sintering temperature and prolonged heating results in evaporation of constituent materials, viz., lithium and oxygen leading to non-stoichiometric, non-homogeneous products with uncontrolled, discontinuous grain growth and increased intragranular porosity. Therefore the properties of the final products are often non-reproducible for having varying characteristics [7]. Technologically it is therefore very difficult to prepare stoichiometric Li-ferrites. Ever since then there has always been an attempt to lower the sintering temperature. The sintering parameters are closely correlated with densification,

\footnotetext{
*Author for correspondence (m_maisnam@yahoo.co.in)
}

microstructural development and hence properties of the finished products $[3,4]$. Uses of sintering aids/flux to lower sintering temperature have been reported by many workers but they do not always meet the purpose. The seconary phases that may arise due to the addition of the flux often deteriorate the important properties [5]. Therefore, in recent times much attention is being paid to the non-conventional chemical methods which offer better option for preparation of Liferrites. These methods are usually very simple, raw materials are inexpensive; do not require elaborate experimental set-up and preparation is less time consuming and hence cost effective. The method ensures mixing of constituent cations at atomic scale in the solution state during the initial stages of preparation with shorter diffusion distances and better homogeneity in mixing. They involve relatively lower sintering temperature for shorter duration with producing better finished products $[7,8]$. Of them, the sol-gel technique provides a simple and economic alternative for preparation of Li-ferrites at reduced temperature. This technique ensures good stoichiometric control, production of nanosized particles with narrow size distribution in a relatively shorter time, good homogeneity, and high sinterability $[9,10]$. Higher heat treatment, as known, is for better crystallization, growth of microstructures and densification [11]. When the ferrite powders are nanosized before sintering, the surface to volume ratio is large and densification shift towards the lower temperature and optimization of density could be achieved at much reduced temperature thus minimizing uncontrolled grain growth and material loss and hence preserving the correct stoichiometry [12]. Moreover, nanoferrites have been the 
subject of current interest as they exhibit different physical properties from their bulk counterparts. The electrical and magnetic properties changes drastically as the particle size goes down to nanometric scale and these deviations widen the scope of applications [13,14]. Pure nano-Liferrites and $\mathrm{Co}^{2+}$ - and $\mathrm{Ni}^{2+}$-doped nano-Li-ferrites have been prepared by the sol-gel auto-combustion technique and they were given heat treatment at different temperatures. The present paper studies the structural like lattice constant, crystallite size, grain size and dielectric properties of these nano-Li-ferrites.

\section{Experimental}

Pure and doped nano-Li-ferrites having compositional formula, viz., $\mathrm{Li}_{0.5} \mathrm{Fe}_{2.5} \mathrm{O}_{4}$ (SA0), $\mathrm{Li}_{0.485} \mathrm{Co}_{0.03} \mathrm{Fe}_{2.485} \mathrm{O}_{4}$ (SA1), and $\mathrm{Li}_{0.43} \mathrm{Ni}_{0.1} \mathrm{Co}_{0.04} \mathrm{Fe}_{2.43} \mathrm{O}_{4}$ (SA2) were prepared by the sol-gel technique. For sample SA0, stoichiometric proportion of high-purity $\mathrm{Fe}\left(\mathrm{NO}_{3}\right)_{2} \cdot 9 \mathrm{H}_{2} \mathrm{O}$ and $\mathrm{LiNO}_{3} \cdot 3 \mathrm{H}_{2} \mathrm{O}$ were dissolved in ethylene glycol in the molar ratio $3: 1$ at $40^{\circ} \mathrm{C}$. The solution was heated at $60^{\circ} \mathrm{C}$ for $30 \mathrm{~min}$ and a wet gel was obtained. The gel was allowed to dry at $80^{\circ} \mathrm{C}$ for another $1 \mathrm{~h}$ after which raising the temperature at $100^{\circ} \mathrm{C}$ the dried gel gets self-ignited itself giving a voluminous and fluffy product. The product thus obtained is the pure nano-Li-ferrite (SA0). For doping $\mathrm{Co}^{2+}$ and $\mathrm{Ni}^{2+}$ in $\mathrm{Li}-$ ferrite, $\mathrm{Co}\left(\mathrm{NO}_{3}\right)_{2} \cdot 6 \mathrm{H}_{2} \mathrm{O}$ and $\mathrm{Ni}\left(\mathrm{NO}_{3}\right)_{2} \cdot 6 \mathrm{H}_{2} \mathrm{O}$, respectively, were included in the starting materials in the required stoichiometric ratio and the procedure was repeated in the same manner as have been performed for the first sample and obtained our other substituted nano-Li-ferrites SA1 and SA2. $\mathrm{X}$-ray diffraction (XRD) were taken on the as-prepared ferrites using Phillips Analytical X'PERT PRO. Then these as-prepared ferrites were grinded in an agate mortar, mixed with polyvinyl alcohol (PVA) (3 wt \%) as binder and pressed into pellets using a hydraulic press and applying a pressure of $100 \mathrm{~kg} \mathrm{~cm}^{-2}$ for $5 \mathrm{~min}$. Pelleted samples were heated at different temperatures, viz., 300 and $500^{\circ} \mathrm{C}$ for $4 \mathrm{~h}$. XRD was also taken on the heat-treated samples and from the XRD data structural informations like lattice constant, X-ray density and crystallite size were evaluated. Curie temperature of the as-prepared samples and the heat-treated samples were measured by Soohoo's method [15]. Electrical contacts using silver coatings were made on both sides of the flat surfaces of the pellets for use in electrical measurements. Room-temperature DC resistivity was determined using the standard two-probe method. Frequency variation of roomtemperature dielectric properties like dielectric constant and dielectric loss tangent were measured using a HP 4284A LCR meter on all the samples from $100 \mathrm{~Hz}$ to $1 \mathrm{MHz}$.

\section{Results and discussions}

The XRD patterns for all the samples are shown in figure 1 . It is found from the patterns that all the samples showed well-defined diffraction peaks, indicating single phase with spinel structure. It can be noted that the as-prepared ferrites showed no extra lines in the patterns out of unreacted materials or impurities even before the heat treatment. The preparation technique used in the present study thus ensured production of pure spinel-structured ferrites. Further heat treatment had served the purpose for improved crystallization and densification. The heat-treated samples showed shift of the peak positions towards the higher angles when compared with the diffraction patterns of the as-prepared samples. The various structural parameters evaluated from

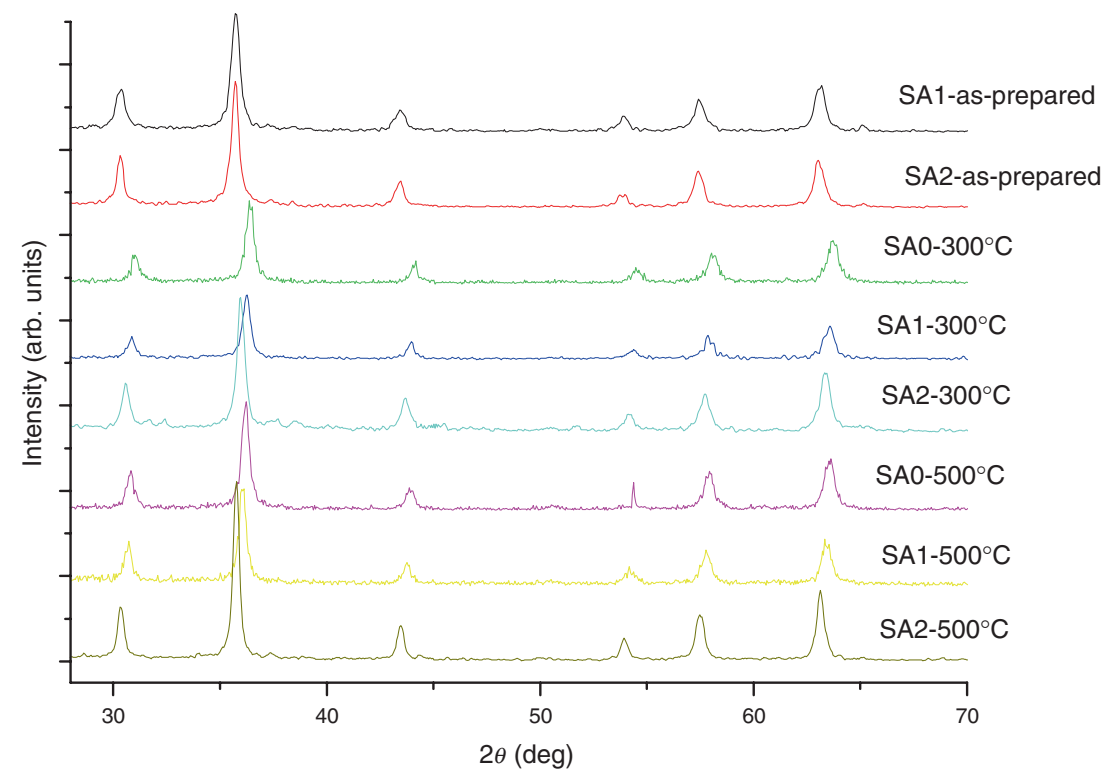

Figure 1. XRD patterns for the as-prepared and different heat-treated nano-Li-ferrites: $\mathrm{Li}_{0.5} \mathrm{Fe}_{2.5} \mathrm{O}_{4}(\mathrm{SA} 0), \mathrm{Li}_{0.485} \mathrm{Co}_{0.03} \mathrm{Fe}_{2.485} \mathrm{O}_{4}(\mathrm{SA} 1)$ and $\mathrm{Li}_{0.43} \mathrm{Ni}_{0.1} \mathrm{Co}_{0.04} \mathrm{Fe}_{2.43} \mathrm{O}_{4}$ (SA2). 
Table 1. Structural, electrical and magnetic data for the as-prepared and different heat-treated nano-Li-ferrites: $\mathrm{Li}_{0.5} \mathrm{Fe}_{2.5} \mathrm{O}_{4}(\mathrm{SA} 0), \mathrm{Li}_{0.485} \mathrm{Co}_{0.03} \mathrm{Fe}_{2.485} \mathrm{O}_{4}(\mathrm{SA} 1)$ and $\mathrm{Li}_{0.43} \mathrm{Ni}_{0.1} \mathrm{Co}_{0.04} \mathrm{Fe}_{2.43} \mathrm{O}_{4}(\mathrm{SA} 2)$.

\begin{tabular}{lcccccc}
\hline Sample & $A(\AA)$ & $d_{\mathrm{x}}\left(\mathrm{g} \mathrm{ml}^{-1}\right)$ & $d_{\mathrm{o}}\left(\mathrm{g} \mathrm{ml}^{-1}\right)$ & $D(\mathrm{~nm})$ & $\rho(\mathrm{M} \Omega \mathrm{cm})$ & $T_{\mathrm{c}}\left({ }^{\circ} \mathrm{C}\right)$ \\
\hline SA1-as-prepared & 8.332 & 4.772 & - & 17 & - & $619 \pm 5$ \\
SA2-as-prepared & 8.336 & 4.835 & - & 18 & - & $609 \pm 5$ \\
SA0-300 ${ }^{\circ}$ & 8.287 & 4.831 & 1.45 & 24.1 & 3.25 & $626 \pm 5$ \\
SA1-300 $\mathrm{C}$ & 8.303 & 4.823 & 1.65 & 18 & 5.01 & $616 \pm 5$ \\
$\mathrm{SA} 2-300^{\circ} \mathrm{C}$ & 8.325 & 4.855 & 1.89 & 19 & 0.18 & $607 \pm 5$ \\
$\mathrm{SA} 0-500^{\circ} \mathrm{C}$ & 8.314 & 4.892 & 2.01 & 24.7 & 3.84 & $635 \pm 5$ \\
$\mathrm{SA} 1-500^{\circ} \mathrm{C}$ & 8.329 & 4.858 & 2.01 & 21 & 5.91 & $628 \pm 5$ \\
$\mathrm{SA} 2-500^{\circ} \mathrm{C}$ & 8.330 & 4.872 & 2.11 & 24 & 0.55 & $627 \pm 5$ \\
\hline
\end{tabular}

the XRD data are tabulated in table 1. The value of lattice constant obtained for the pure Li-ferrites at both the heating conditions are found to be close to the standard value $\sim 8.329 \AA$ [16], indicating that the synthesizing technique preserved the stoichiometry of Li-ferrites. For similar heating conditions an increase in lattice size has been observed with metal ions substitution which may be due to the substitution of the bigger sized metal ions $\left(\mathrm{Co}^{2+}, \mathrm{Ni}^{2+}\right)$ in place of the smaller ones $\left(\mathrm{Li}^{+}, \mathrm{Fe}^{3+}\right)$ as can also be seen from the compositional formula. Before heat treatment, both the substituted Li-ferrites are found with larger value of lattice constant and upon heat treatment the value decreased (table 1). The diffraction peaks for the heated samples shift towards relatively higher angles and the lattice constant decreased towards that of the stoichiometric value (figure 1 and table 1).

The crystallite size of the samples calculated from the XRD data using the Scherrer formula are depicted in table 1. The samples are found with nanosized crystallites $\sim 17-24 \mathrm{~nm}$ and the size increased with heat treatment. Sol-gel derived particles with good cystallinity when heated at temperature as low as $\sim 400^{\circ} \mathrm{C}$ have been reported by others [17]. However the present samples have shown spinel phased nanocrystallites of size $\sim 17-18 \mathrm{~nm}$ in the as-prepared samples obtained at temperature $\sim 100^{\circ} \mathrm{C}$ (table 1 ). After heat treatment the density, crystallite size increased and this agrees with the reports from other workers which showed better crystallinity, higher densification and growth of microstructures with heat treatment $[11,18]$. Scanning electron microscopy (SEM) photomicrographs were taken on all the samples to study the microstructures. A typical SEM photomicrograph for sample SA2 heated at $500^{\circ} \mathrm{C}$ is shown in figure $2 \mathrm{a}$. The figure shows grains of sizes $32-56 \mathrm{~nm}$. The comparatively bigger microstructures observed in the SEM photomicrographs may be because of the formation of agglomerates constituted of large number of finer nanocrystallites. One of the reasons for such cohesion of finer crystallites to form larger grains may be due to the magnetic attraction among the finer nanocrystallites. The grains are however cubical in shape with narrow size distribution. An EDX spectrum for this sample is depicted in figure $2 \mathrm{~b}$. The figure showed peaks assigned to $\mathrm{Fe}, \mathrm{Co}, \mathrm{O}$ and $\mathrm{Ni}$ suggesting that they are the main constituents in the sample (Li could not be observed in the spectra), which actually are for the sample SA2. Similar observations have been obtained for the other samples.

The values of Curie temperature measured on the samples are depicted in table 1 . It is found to be close to the standard value for stoichiometic Li-ferrites [19] and the value increased with the increase in heating temperature. However, the substituted Li-ferrites showed lower value of Curie temperature compared with that of pure Li-ferrites. Doping with $\mathrm{Ni}^{2+}$ and $\mathrm{Co}^{2+}$ replaced the $\mathrm{Fe}^{3+}$ ions in the ferrites thereby decreasing the Fe-linkages and hence caused to lower the Curie temperature. Room-temperature d.c. resistivity, ' $\rho$ ' was measured on the heat-treated samples and in all the three samples higher temperature heating improved the $\rho$-values (table 1). Reports have shown that $\rho$-values drops due to the presence of localized states in the forbidden energy gap which arises out of lattice imperfections and their presence effectively lowers the energy barrier to the flow of electrons [18]. Heat treatment improved the stoichiometry resulting in reducing imperfections thus improving the resistivity of the samples.

Dielectric measurements from the pelleted as-prepared samples showed very poor dielectric behaviour but improvements have been observed in the heat-treated samples as seen in figure 3 . The figure showed the frequency dependence of the dielectric constant, $\varepsilon^{\prime}$ for all the samples in the range of $100 \mathrm{~Hz}-1 \mathrm{MHz}$. It is observed from the figures that $\varepsilon^{\prime}$ initially decreased rapidly with frequency upto about $4 \mathrm{kHz}$ followed by a slow decrease from 4 to $30 \mathrm{kHz}$ and beyond 30 $\mathrm{kHz}$ it remained nearly constant. The observed variation of $\varepsilon^{\prime}$ is the normal dielectric behaviour of ferrites which showed dispersion due to Maxwell-Wagner [20] type of interfacial polarization and in agreement with Koop's phenomenological model [21]. The $\varepsilon^{\prime}$-value is quite low, about $10-10^{2}$ times lower than those measured in Li-ferrites prepared by the conventional ceramic technique $[22,23]$. The present solgel derived samples being treated at lower temperature, the chances of $\mathrm{Li}$ and $\mathrm{O}$ volatility and hence the formation of $\mathrm{Fe}^{2+}$ ions at the B-sites of the spinel lattice during synthesis are reduced, thus preserving the desired stoichiometry and reducing the imperfections in the samples. The electron exchanges between +2 and $+3 \mathrm{Fe}$-ions at the B-sites and 
(a)

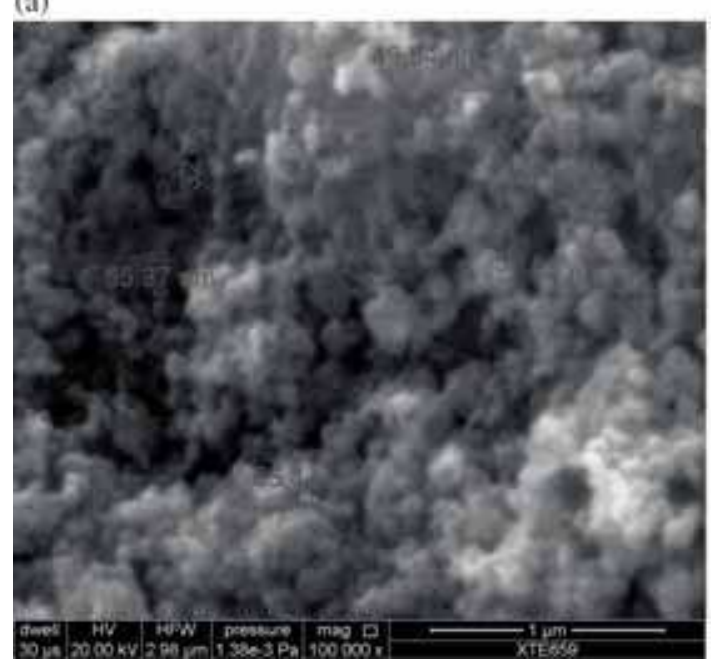

(b)

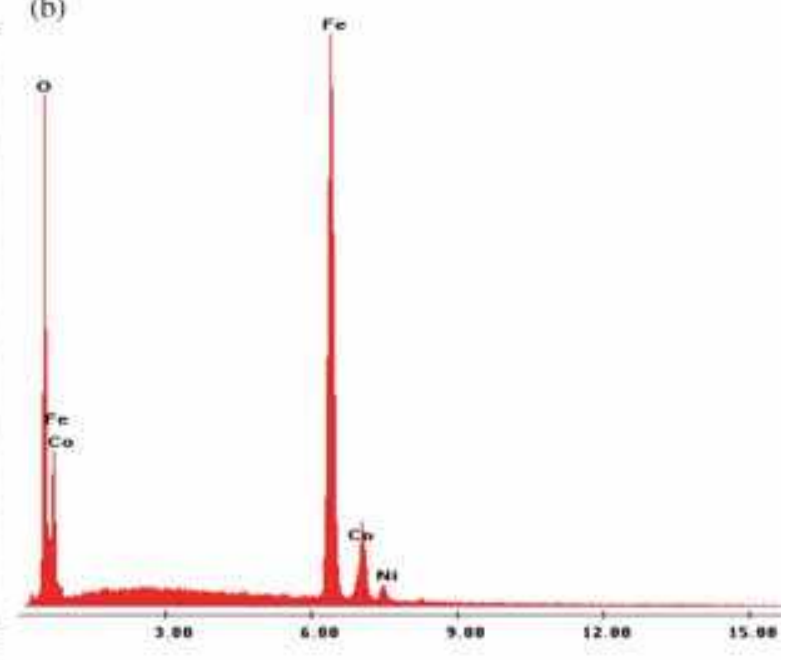

Figure 2. (a) SEM photomicrograph and (b) EDX spectra for $\mathrm{Li}_{0.43} \mathrm{Ni}_{0.1} \mathrm{Co}_{0.04} \mathrm{Fe}_{2.43} \mathrm{O}_{4}$ (SA2) nanoferrites heated at $500^{\circ} \mathrm{C}$.

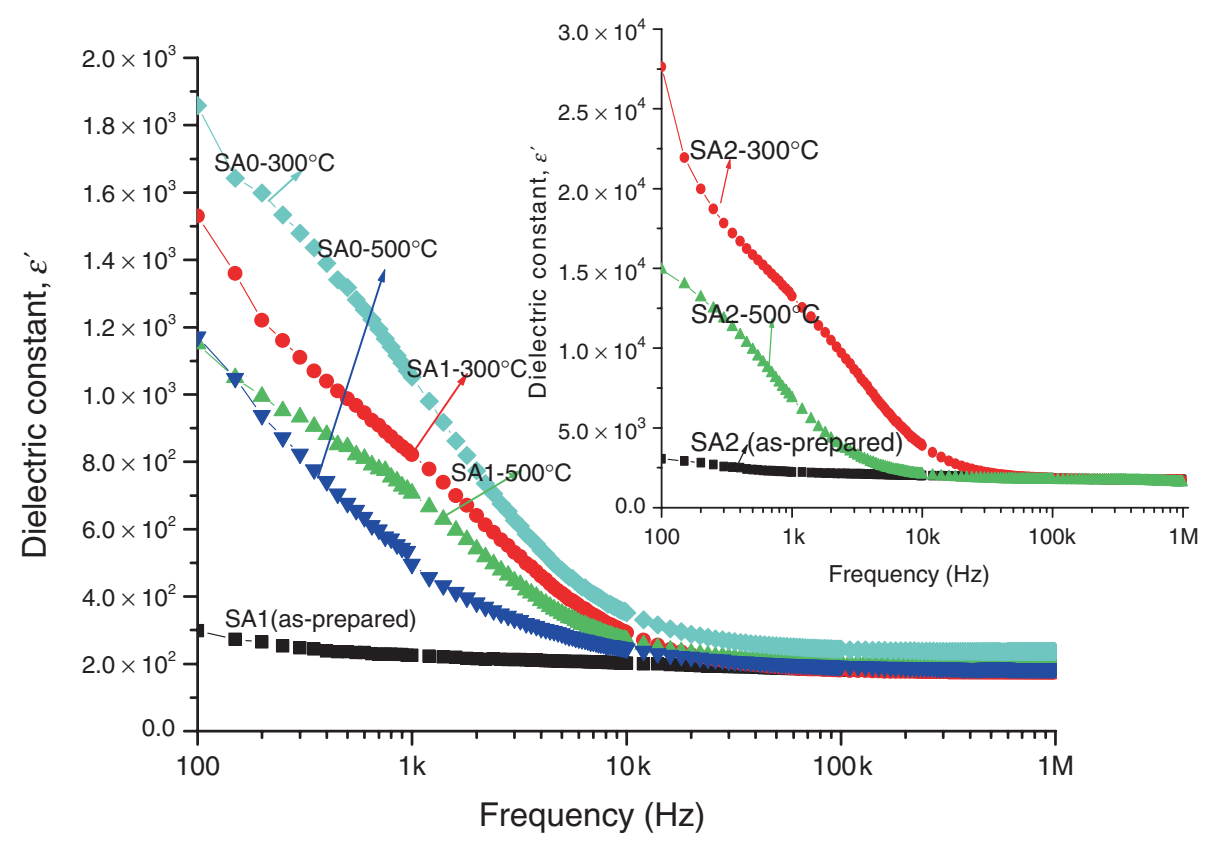

Figure 3. Frequency variation of dielectric constant, $\varepsilon^{\prime}$ for the as-prepared and different heat-treated nano-Li-ferrites: $\mathrm{Li}_{0.5} \mathrm{Fe}_{2.5} \mathrm{O}_{4}(\mathrm{SA} 0), \mathrm{Li}_{0.485} \mathrm{Co}_{0.03} \mathrm{Fe}_{2.485} \mathrm{O}_{4}$ (SA1) and $\mathrm{Li}_{0.43} \mathrm{Ni}_{0.1} \mathrm{Co}_{0.04} \mathrm{Fe}_{2.43} \mathrm{O}_{4}$ (SA2).

hence polarization effect are restricted therefore $\varepsilon^{\prime}$-values drops to large extent as expected. This can also be understood from the increase of d.c. resistivity with higher heat treatment (table 1) which consequently reduced the value of $\varepsilon^{\prime}$. Furthermore, compared with the ferrites prepared by the ceramic method [22,23], the very small nanometric crystallites obtained in the sol-gel derived samples have greater number of insulating grain boundaries that acts as scattering centres to the conduction of electrons thereby restricting electron exchanges and hence polarization decreased. The small crystallites also provide large surface to volume ratio with greater probability for converting the $\mathrm{Fe}^{2+}$ ions which might have formed back to $\mathrm{Fe}^{3+}$ ions. Therefore the chance of electron hopping between $\mathrm{Fe}^{2+}$ and $\mathrm{Fe}^{3+}$ ions to produce polarization is least feasible. Hence, the reduced $\varepsilon^{\prime}$-value for these nanocrystallites compared to the micronsized crystallites prepared by the ceramic technique. Such reduction in $\varepsilon^{\prime}$-values is preferred for high-frequency applications as low $\varepsilon^{\prime}$ increases the penetration dept of electromagnetic waves and reduces skin effect [24]. 


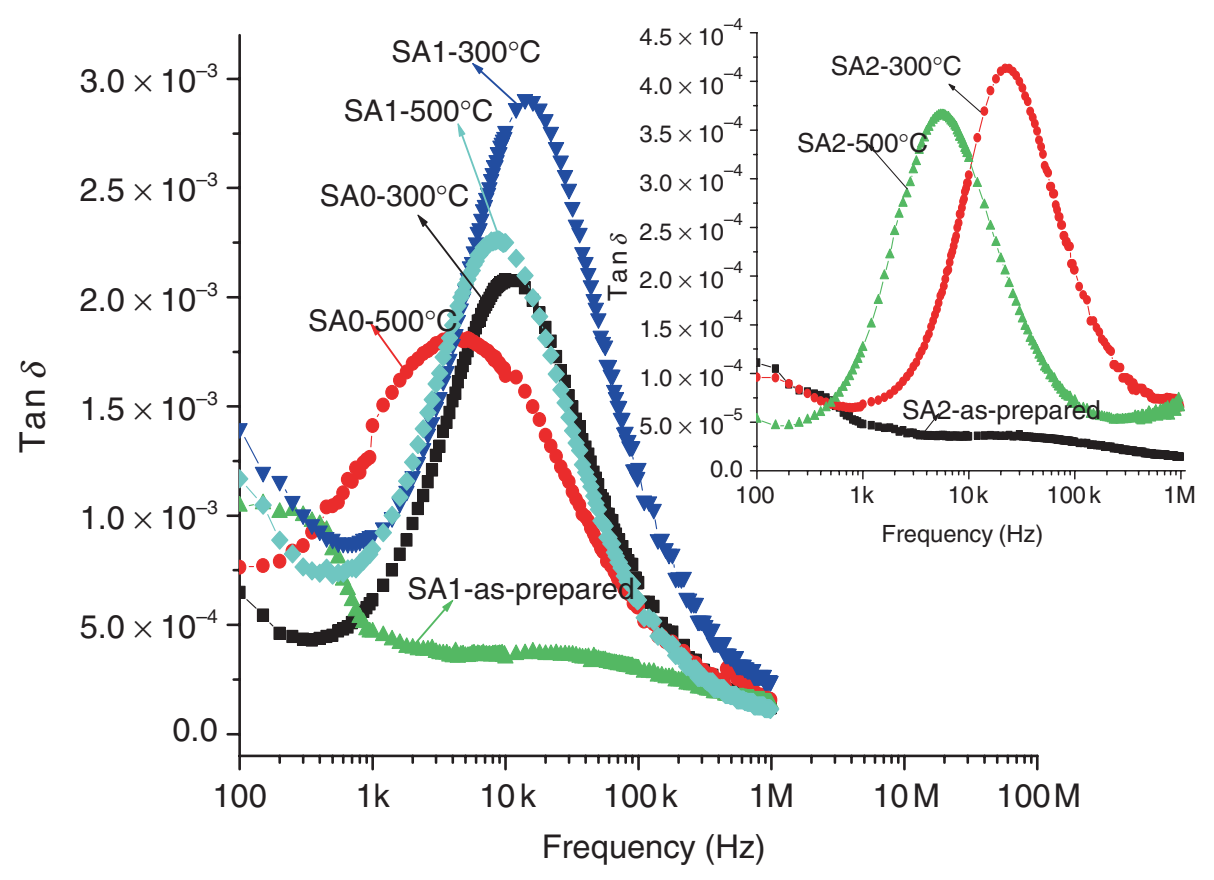

Figure 4. Frequency variation of dielectric loss tangent, $\tan \delta$ for the as-prepared and different heat-treated nano-Li-ferrites: $\mathrm{Li}_{0.5} \mathrm{Fe}_{2.5} \mathrm{O}_{4}(\mathrm{SA} 0), \mathrm{Li}_{0.485} \mathrm{Co}_{0.03} \mathrm{Fe}_{2.485} \mathrm{O}_{4}$ (SA1) and $\mathrm{Li}_{0.43} \mathrm{Ni}_{0.1} \mathrm{Co}_{0.04} \mathrm{Fe}_{2.43} \mathrm{O}_{4}(\mathrm{SA} 2)$.

The variation dielectric loss tangent, $\tan \delta$ with frequency for the different samples is shown in figure 4 . This loss is the result of the lag in polarization in accordance with the applied electric field. It is found that the loss tangent values obtained are much smaller, of about 2-4 orders of magnitude lower than those measured from samples prepared by the ceramic technique $[22,23]$. The decrease in crystallite size to nanometric scale has been found to produce tremendous reduction in the value of $\tan \delta$. The value of $\tan \delta$ depends on a number of factors such as composition, synthesis technique, stoichiometry, hence $\mathrm{Fe}^{2+}$ ion content and structural homogeneity. As discussed above, the presence of $\mathrm{Fe}^{2+}$ ion are related with the dielectric constant and hence dielectric loss tangent, $\tan \delta$ of ferrites. The reduced loss obtained may be due to minimized hopping effect [25-27]. Tan $\delta$ showed maxima with frequency and samples heated at lower temperature were found to exhibit higher maxima peak. The occurrence of peak is viewed from the strong correlation between the conduction mechanism and the dielectric behaviour for spinel ferrites. Loss maximum is observed when the hopping frequency of the polarizable charges becomes equal to the externally applied electric field [28]. The figure also showed that maxima of $\tan \delta$ shift towards lower frequency with the increase in heating temperature. Having obtained very low value of $\tan \delta$ with the synthesis techniques employed, further investigation look forward to an attempt to increase the density close to theoretical value with the increase in temperature of heating and thereafter the studies of their structural, electrical and magnetic properties.

\section{Conclusion}

$\mathrm{Li}_{0.5} \mathrm{Fe}_{2.5} \mathrm{O}_{4} \quad(\mathrm{SA} 0), \quad \mathrm{Li}_{0.485} \mathrm{Co}_{0.03} \mathrm{Fe}_{2.485} \mathrm{O}_{4} \quad(\mathrm{SA} 1)$ and $\mathrm{Li}_{0.43} \mathrm{Ni}_{0.1} \mathrm{Co}_{0.04} \mathrm{Fe}_{2.43} \mathrm{O}_{4}$ (SA2) nanoferrites have been prepared by the sol-gel autocombustion technique. Nanoferrites with single-phase spinel structure have been formed in the as-prepared samples even before the heat treatment. Density, crystallite size and resistivity were improved with heat treatment. The prepared nanoferrites showed very low values of dielectric loss tangent, of about 2-4 orders of magnitude lower than those measured from ferrites prepared by the ceramic technique. The frequency variation of the dielectric behaviour showed the normal dielectric dispersion behaviour.

\section{References}

[1] Smith J and Wijn H P J 1959 Ferrites (London: Cleave-Hume Press Ltd.)

[2] Argentina G M and Baba P D 1974 IEEE Trans. Microwave Theory Tech. MTT-22 652

[3] Bandhyopadhyay G and Fulrath R M 1974 J. Am. Ceram. Soc. 57182

[4] Baba P D, Argentina G M, Courtney W E, Dionne G F and Temme D H 1972 IEEE Trans. Magn. MAG-8 83

[5] Kishan P 1993 Microwave materials (New Delhi, India: Narosa Publishing House)

[6] Cho Y S, Burdick V L and Amarakoon V R W 1999 J. Am. Ceram. Soc. 821416 
[7] Verma A, Goel T C and Mendiratta R G 2000 Mater. Sci. Technol. 16712

[8] Pathan T and Shaikh A M 2012 Eur. J. Appl. Eng. Sci. Res. 1 173

[9] Sutradhar S, Pati S, Acharya S, Das S and Chakrabarti P K 2012 J. Magn. Magn. 3241317

[10] Waluyo N S, Almajid A A and Soliman M A 2012 Adv. Mater. Res. 4631468

[11] Gee S H, Hong Y K, Park M H, Erickson D W and Lamb P J 2002 J. Appl. Phys. 917586

[12] Murthy S R 2001 Bull. Mater. Sci. 24379

[13] Ali A Z, Abdeltwab E and Abbas Y 2009 J. Ovonic Res. 5157

[14] Maaz K, Karim S, Mumtaz A, Hasanain S K, Liu J and Duan J L 2009 J. Magn. Magn. 3211838

[15] Soohoo R F 1960 Theory and application of ferrites (New Jersey: Prentice Hall)

[16] Ridgley D H, Lessoff H and Childress J D 1970 J. Am. Ceram. Soc. 6304
[17] Jacob P, Kumar A, Pant R P, Singh S and Mohammed E M 2011 Bull. Mater. Sci. 341345

[18] George M, Nair S S, John A M, Joy P A and Anantharaman M R 2006 J. Phys. D: Appl. Phys. 39900

[19] Kishan P, Chatterjee S N, Nagpaul L K and Laroia K K 1981 Ind. J. Pure Appl. Phys. 1983

[20] Wagner K W 1913 Ann. Phys. 40817

[21] Koops G 1951 Phys. Rev. 83121

[22] Watawe S C, Sarwade B D, Bellad S S, Sutar B D and Chougule B K 2000 J. Magn. Magn. 21455

[23] Maisnam M, Phanjoubam S, Sarma H N K, Thakur O P, Devi L R and Prakash C 2003 Int. J. Mod. Phys. B 173881

[24] Nasir S and Anis-ur Rehman M 2011 Phys. Scr. 841

[25] Raman R and Murthy V R K 1991 J. Appl. Phys. 694053

[26] Dar M A, Verma V, Gairola S P, Siddiqui W A, Singh R K and Kotnala R K 2012 Appl. Surf. Sci. 2585342

[27] Mansour S F and Elkestawy M A 2011 Ceram. Int. 371175

[28] Iwauchi K 1971 Jpn. J. Appl. Phys. 101520 